\title{
Effect of Matrix Substructures on Precipitation of the Laves Phase in $\mathrm{Fe}-\mathrm{Cr}-\mathrm{Nb}-\mathrm{Ni}$ System
}

\author{
Keisuke YAMAMOTO, Yoshisato KIMURA ${ }^{11}$ and Yoshinao MISHIMA ${ }^{11}$
}

Graduate Student, Department of Materials Science and Technology, Tokyo Institute of Technology, 4259 Nagatsuta, Midori-ku, Yokohama 227-8502 Japan. $\quad 1$ 1) Department of Materials Science and Technology, Tokyo Institute of Technology, 4259 Nagatsuta, Midori-ku, Yokohama 227-8502 Japan.

(Received on November 18, 2002; accepted in final form on February 7, 2003)

\begin{abstract}
In order to make clear the effect of matrix substructures on the Laves phase precipitation in $\mathrm{Fe}-\mathrm{Cr}-\mathrm{Nb}-\mathrm{Ni}$ system, age hardening behavior was examined during isothermal aging up to $1000 \mathrm{~h}$ at 873 and $973 \mathrm{~K}$ and the precipitation morphology of the Laves phase was investigated by transmission electron microscopy (TEM). The microstructures of $\mathrm{Fe}-10 \mathrm{Cr}-1 \mathrm{Nb}$ and $\mathrm{Fe}-15 \mathrm{Cr}-1 \mathrm{Nb}(\mathrm{mol} \%)$ alloys with ferrite matrix contain high density of rod-shaped Laves phase which precipitates within the ferrite grains during aging. On the other hand, in the $\mathrm{Fe}-10 \mathrm{Cr}-1 \mathrm{Nb}-1 \mathrm{Ni}$ alloy with massive ferrite matrix, most of the Laves phase precipitates in subgrain boundaries. Additionally the deformed ferrite matrix has been prepared for examining the effect of dislocation density on morphology of the Laves phase. It is found that the difference of matrix substructures between the ferrite and deformed ferrite provides the different number and distribution of nucleation sites for precipitation of the Laves phase. Mechanical properties were evaluated by tensile tests conducted at room temperature, 873 and $973 \mathrm{~K}$.
\end{abstract}

KEY WORDS: precipitation; microscopy.

\section{Introduction}

High Cr ferritic heat resistant steels are widely used in power generating plants because of their high creep strength and superior oxidation resistance. Conventional ferritic steels are usually based on tempered martensite and their creep strength is sustained by precipitation hardening of MC carbides and MX carbonitrides as well as by solid solution hardening of $\mathrm{Mo}, \mathrm{V}, \mathrm{Nb}$ and $\mathrm{Ti}$. The precipitation sequence in high $\mathrm{Cr}$ ferritic steels has been revealed to be quite complicated as that it involves precipitation of some meta-stable and stable intermetallic phases other than $\mathrm{MC}$ carbides and MX carbonitrides. Recently, C14 type Laves phases have drawn a growing interest as strengthener to improve the creep resistance of the steels. ${ }^{1)}$

Laves phases are $\mathrm{A}_{2} \mathrm{~B}$-type intermetallic compounds with TCP (Topologically Close Packed) structures; hexagonal (C14 and C36) and cubic (C15). These structures are expected to have high strength at elevated temperatures. Uchida et $a l .{ }^{2)}$ found that the creep rupture strength was improved by the additions of Mo, W and $\mathrm{Ti}$ to $2.25 \mathrm{wt} \% \mathrm{Cr}$ ferritic steels due to the precipitation of Laves phases $\left(\mathrm{Fe}_{2} \mathrm{Mo}, \mathrm{Fe}_{2} \mathrm{~W}\right.$ and $\left.\mathrm{Fe}_{2} \mathrm{Ti}\right)$ during tempering. Also it is suggested that fine precipitation of the Laves phase $\mathrm{Fe}_{2} \mathrm{~W}$ under the service condition improves the creep resistance of recently developed ferritic steels containing $\mathrm{W}^{3)}$ It has been pointed out, however, that the precipitation of the Laves phase reduces toughness of the steels particularly at ambient temperature because of its poor deformability due to the complicated crystal structure. ${ }^{4)}$

The difference of matrix substructures could affect the morphology of precipitates. Number of nucleation sites for the precipitation increases with increasing excess energy arising from defects in matrix substructures. It is necessary to understand the effect of matrix substructures on the precipitation behavior for the present alloy design based on precipitation hardening of the Laves phase. Suzuki et al. ${ }^{5}$ ) systematically investigated the age-hardening behavior of maraging steels and ferrite matrix steels and showed that the activation energy of precipitation in the martensite matrix is generally lower than that in the ferrite. Maruyama et $a l{ }^{6)}$ have investigated the precipitation and phase transformation of copper particles in low alloy ferritic and martensitic steels to show that the precipitation of copper particles and the corresponding hardening behavior in the martensite matrix are different from that in the ferrite. The main reason for this difference is considered to be responsible for the much higher dislocation density in martensite than in ferrite.

The present authors have made every effort to establish the basis of the development of carbon-free ferritic heat resistant steels in which the Laves phase is solely the strengthener in the ferrite matrix. ${ }^{7)}$ In the ternary $\mathrm{Fe}-\mathrm{Cr}-\mathrm{Nb}$ system, it is possible to design the two-phase alloys consisting of $\alpha$-Fe and $\mathrm{C} 14 \mathrm{Fe}_{2} \mathrm{Nb}$ which are stable up to high temperatures at around $10 \mathrm{at} \% \mathrm{Cr}$. With the addition of an austenite former $\mathrm{Ni}$, the $\gamma / \alpha$ transformation can be involved in the quaternary $\mathrm{Fe}-\mathrm{Cr}-\mathrm{Nb}-\mathrm{Ni}$ system. Utilizing the $\gamma / \alpha$ 
transformation through proper adjustment in alloy chemistry and heat treatment provides various types of $\alpha$-Fe matrix substructure, and thereby we believe it is possible to modify the morphology of the Laves phase precipitates in $\alpha$-Fe matrix by selecting its substructure. Consequently, we could improve elevated temperature strength as well as toughness of the ferritic steels. The objective of the present study is to investigate the effects of $\alpha$-Fe matrix substructures on the morphology and thermal stability of the Laves phase, $\mathrm{Fe}_{2} \mathrm{Nb}$, precipitation in $\mathrm{Fe}-\mathrm{Cr}-\mathrm{Nb}-\mathrm{Ni}$ system. Variations of the $\alpha$-Fe matrix substructure widely controlled in this work are ferrite, massive ferrite. Additionally, the deformed ferrite matrix has been prepared for examining the effect of dislocation density on the Laves phase precipitates. Moreover mechanical properties were investigated to evaluate high temperature strength and ambient temperature ductility.

\section{Experimental Procedure}

Nominal compositions of the alloys used in the present study are $\mathrm{Fe}-10 \mathrm{Cr}-1 \mathrm{Nb}, \mathrm{Fe}-10 \mathrm{Cr}-1 \mathrm{Nb}-1 \mathrm{Ni}$ and $\mathrm{Fe}-15 \mathrm{Cr}-$ $1 \mathrm{Nb}$ in $\mathrm{mol} \%$. The corresponding alloy compositions in wt $\%$ are $\mathrm{Fe}-9.3 \mathrm{Cr}-1.7 \mathrm{Nb}, \mathrm{Fe}-9.3 \mathrm{Cr}-1.7 \mathrm{Nb}-1 \mathrm{Ni}$ and $\mathrm{Fe}-$ $14 \mathrm{Cr}-1.7 \mathrm{Nb}$ respectively. They were prepared by induction melting in an alumina crucible and casting into a mold in an argon atmosphere. The ingots of about $300 \mathrm{~g}(30 \mathrm{~mm}$ in diameter and $50 \mathrm{~mm}$ in height) were then hot rolled at $1373 \mathrm{~K}$ to a reduction ratio of $80 \%$ in thickness. Temperature of the ingots at the final rolling path was monitored at least higher than $1073 \mathrm{~K}$ by a radiation thermometer.

The $\gamma / \alpha$ transformation temperature was determined by a dilatometer. The cylindrical specimens with the size of $3 \mathrm{~mm}$ in diameter and $10 \mathrm{~mm}$ in height were machined from the as-hot-rolled plates. Specimens were heated to $1273 \mathrm{~K}$ at $8 \mathrm{~K} \mathrm{~min}^{-1}$, held for $5 \mathrm{~min}$, and cooled to room temperature at $50 \mathrm{~K} \mathrm{~min}^{-1}$.

Tensile specimens with the dimension of $15 \mathrm{~mm}$ in gage length, $3 \mathrm{~mm}$ in width and $1 \mathrm{~mm}$ in thickness were prepared by electrodischarge machining from the rolled plate. The tensile tests were carried out on as-rolled specimens and those annealed at $1023 \mathrm{~K}$ for $1 \mathrm{~h}$. The tests were carried out at the initial strain rate of $1.1 \times 10^{-4} \mathrm{~s}^{-1}$ at room temperature, 873 and $973 \mathrm{~K}$ in a vacuum of about $10^{-4}$ torr. Loading direction was chosen as to be parallel to the rolling direction.

Age hardening behavior was examined on as-hot-rolled materials by measuring the hardness change during isothermal aging for 0.1 to $1000 \mathrm{~h}$ at 873 and $973 \mathrm{~K}$. MicroVickers tests were conducted for this purpose under $1 \mathrm{~kg}$ load.

Microstructures of the alloys were observed by optical microscope (OM), scanning electron microscope (SEM), and transmission electron microscope (TEM) at an accelerating voltage of $200 \mathrm{kV}$. The specimens for observations by $\mathrm{OM}$ and SEM were mechanically polished and then etched in a picric acid solution. The SEM observations were done by using back-scattered electron images of compositional mode. Thin foils for TEM observation were prepared by twin-jet electropolishing using a solution of $10 \%$ perchloric acid and $90 \%$ methanol at below $223 \mathrm{~K}$. The TEM observations were carried out by using bright field images and selected area diffraction (SAD) patterns for structure analysis.

\section{Results and Discussion}

\subsection{Control of the Matrix Substructures}

It is possible to modify the morphology of the Laves phase precipitates by controlling substructure of the $\alpha$-Fe matrix by selecting alloy compositions and heat treatments. Table 1 summarizes the matrix substructures and notations of the alloys. The alloys are hereafter expressed by chromium and nickel concentrations in $\mathrm{mol} \%$ and the characteristic of matrix substructure, for example, the $\mathrm{Fe}-10 \mathrm{Cr}-1 \mathrm{Nb}-$ $0 \mathrm{Ni}(\mathrm{mol} \%)$ alloy with ferrite matrix is denoted as $10-0-\mathrm{F}$. Two types of matrix substructures, massive ferrite (10-1MF alloy) and ferrite (10-0-F, 15-0-F alloy), are provided by utilizing the $\gamma / \alpha$ transformation. The $\gamma / \alpha$ transformation temperatures are listed in Table 2. Since 10-0-F and 15-0F alloys have no $\gamma / \alpha$ transformation, the matrix of these alloys is ferrite. With the addition of $1 \mathrm{~mol} \% \mathrm{Ni}$, the $\operatorname{Ar}_{3}(\gamma / \alpha$ transformation temperature during cooling) point appears at about $823 \mathrm{~K}$ in $10-1-\mathrm{MF}$ alloy. This $\mathrm{Ar}_{3}$ temperature is far above the $\mathrm{M}_{\mathrm{s}}$ temperature (starting martensitic transformation temperature) which is estimated to be $603 \mathrm{~K}$ by the empirical calculation using concentrations of ferrite forming and austenite forming elements. $\left.{ }^{8}\right)$ Therefore the massive transformation from $\gamma$-Fe to $\alpha$-Fe takes place during cooling in the 10-1-MF alloy instead of the martensitic transformation. In low-carbon and ultra low-carbon steels, it is known that the transformation temperature of massive ferrite formation is higher than the Ms temperature. ${ }^{9)}$

\subsubsection{Microstructures of the As-hot-rolled Alloys}

The back-scattered electron images of the as-hot-rolled $10-0-\mathrm{F}$ and $10-1-\mathrm{MF}$ alloys on their transverse sections are shown in Fig. 1. The bright phase is $\mathrm{Fe}_{2} \mathrm{Nb}$, and the dark phase is $\alpha$-Fe matrix. The microstructure of the $10-0$ $\mathrm{F}$ alloy shown in Fig. 1(a) consists of ferrite matrix and a small amount of $\mathrm{Fe}_{2} \mathrm{Nb}$ particles. In the 10-1-MF alloy, $\gamma$ $\mathrm{Fe}$ and $\mathrm{Fe}_{2} \mathrm{Nb}$ should coexist with each other at the temperature that hot-rolling was employed, and the $\gamma$-Fe matrix transforms to massive ferrite upon subsequent cooling. As shown in Fig. 1(b), the matrix is massive ferrite with irregular boundaries, in which the fine spherical $\mathrm{Fe}_{2} \mathrm{Nb}$ precipitates are dispersed uniformly.

Table 1. Characteristics of the matrix microstructure of the experimental alloys.

\begin{tabular}{r|c|l}
\hline Alloys (mol\%) & Matrix (symbol) & Notation \\
\hline Fe-10Cr-1Nb-0Ni & Ferrite (F) & $10-0-\mathrm{F}$ \\
Fe-15Cr-1Nb-0Ni & Ferrite (F) & $15-0-\mathrm{F}$ \\
Fe-10Cr-1Nb-1Ni & Massive ferrite (MF) & $10-1-\mathrm{MF}$ \\
\hline
\end{tabular}

Table 2. $\gamma-\alpha$ transformation temperatures of the experimental alloys.

\begin{tabular}{c|cccc}
\hline Alloys & \multicolumn{5}{|c}{$\gamma-\alpha$ transformation temperature (K) } \\
& $\alpha \rightarrow \alpha+\gamma$ & $\alpha+\gamma \rightarrow \gamma$ & $\gamma \rightarrow \alpha+\gamma$ & $\alpha+\gamma \rightarrow \alpha$ \\
\hline $10-0-\mathrm{F}, 15-0-\mathrm{F}$ & $*$ & $*$ & $*$ & $*$ \\
$10-1-\mathrm{MF}$ & 1103 & 1133 & 823 & 733 \\
\hline
\end{tabular}



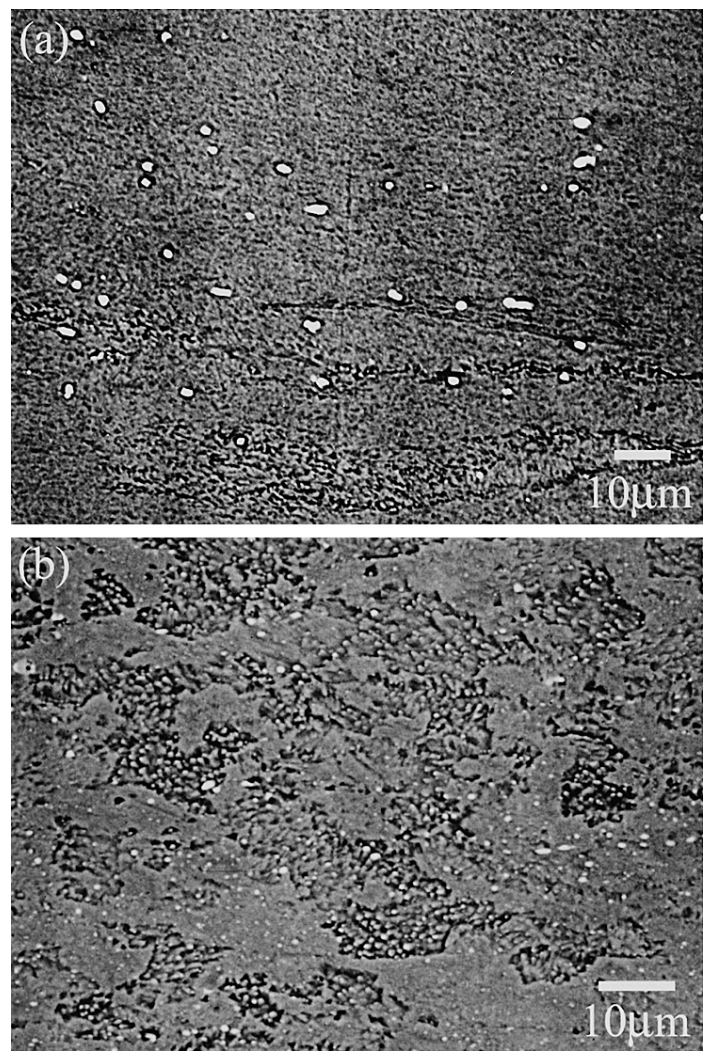

Fig. 1. Back scattered electron images of as-rolled alloys, (a) 10-0-F, (b) 10-1-MF.

The bright field images of the as-hot-rolled 10-0-F and 10-1-MF alloys are shown in Fig. 2. As shown in Fig. 2(a), the dislocation density in the ferrite matrix is low in $10-0-\mathrm{F}$ alloy. Fine $\mathrm{Fe}_{2} \mathrm{Nb}$ particles of about a few hundreds $\mathrm{nm}$ in size which presumably form during hot rolling are located along the ferrite grain boundaries. On the other hand, the cellular substructure with high dislocation density is the microstructural feature of the matrix in 10-1-MF alloy, and spherical $\mathrm{Fe}_{2} \mathrm{Nb}$ precipitates with less than $1 \mu \mathrm{m}$ in diameter are distributed in the matrix as shown in Fig. 2(b). It is noted that $\mathrm{Fe}_{2} \mathrm{Nb}$ exists in the as-hot-rolled microstructure of the $10-0-\mathrm{F}$ and $10-1-\mathrm{MF}$ alloys because both the alloys are consisting of the two-phase $\alpha-\mathrm{Fe} / \mathrm{Fe}_{2} \mathrm{Nb}$ microstructure at hot-rolled temperature.

\subsubsection{Microstructures of the Annealed Alloys}

Figure 3 shows a bright field image and the corresponding selected area diffraction (SAD) of $10-0-\mathrm{F}$ alloy annealed at $1023 \mathrm{~K}$ for $1 \mathrm{~h}$. The microstructure consists of numbers of rod-shaped precipitates and the ferrite matrix. These fine precipitates are identified as $\mathrm{Fe}_{2} \mathrm{Nb}$ Laves phase with the C14 crystal structure, which must have secondarily precipitated upon annealing.

The crystallographic orientation relationship between the $\mathrm{C} 14 \mathrm{Fe}_{2} \mathrm{Nb}$ phase and bcc matrix is analyzed using SAD patterns as $(0001)_{\mathrm{Fe}_{2} \mathrm{Nb}} / /(211)_{\alpha \text {-Fe }}$ and $[4 \overline{5} 10]_{\mathrm{Fe}_{2} \mathrm{Nb}} / /[31 \overline{7}]_{\alpha-\mathrm{Fe}}$ (Figs. 3(b), 3(c)). Figure 4 gives the stereographic projection of the orientation relationship between $\alpha$-Fe and $\mathrm{Fe}_{2} \mathrm{Nb}$ Laves phase. This orientation relationship is equivalent to the following expression by lower mirror indices; $(0001)_{\mathrm{Fe}_{2} \mathrm{Nb}} / /(211)_{\alpha-\mathrm{Fe}},[\overline{2} 110]_{\mathrm{Fe}_{2} \mathrm{Nb}} / /[0 \overline{1} 1]_{\alpha-\mathrm{Fe}}$, and $[01 \overline{1} 0]_{\mathrm{Fe}_{2} \mathrm{Nb}} / /$ $[\overline{1} 11]_{\alpha-\mathrm{Fe}}$. Note that the orientation relationship obtained
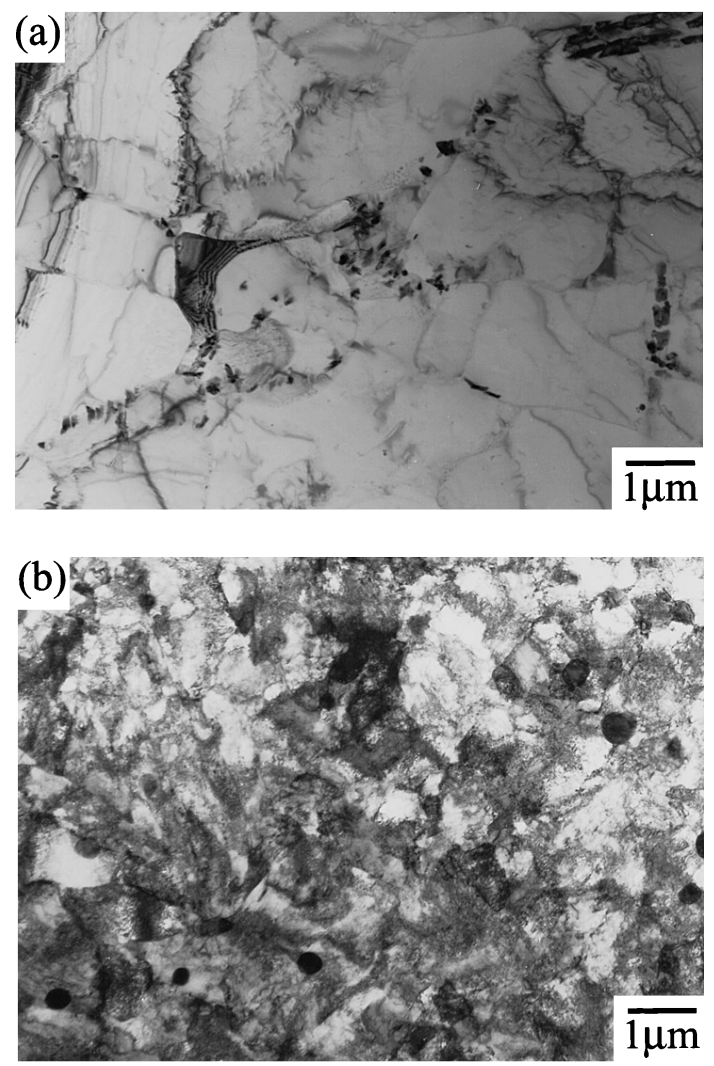

Fig. 2. Bright field images of as-rolled alloys, (a) 10-0-F, (b) 10-1-MF.
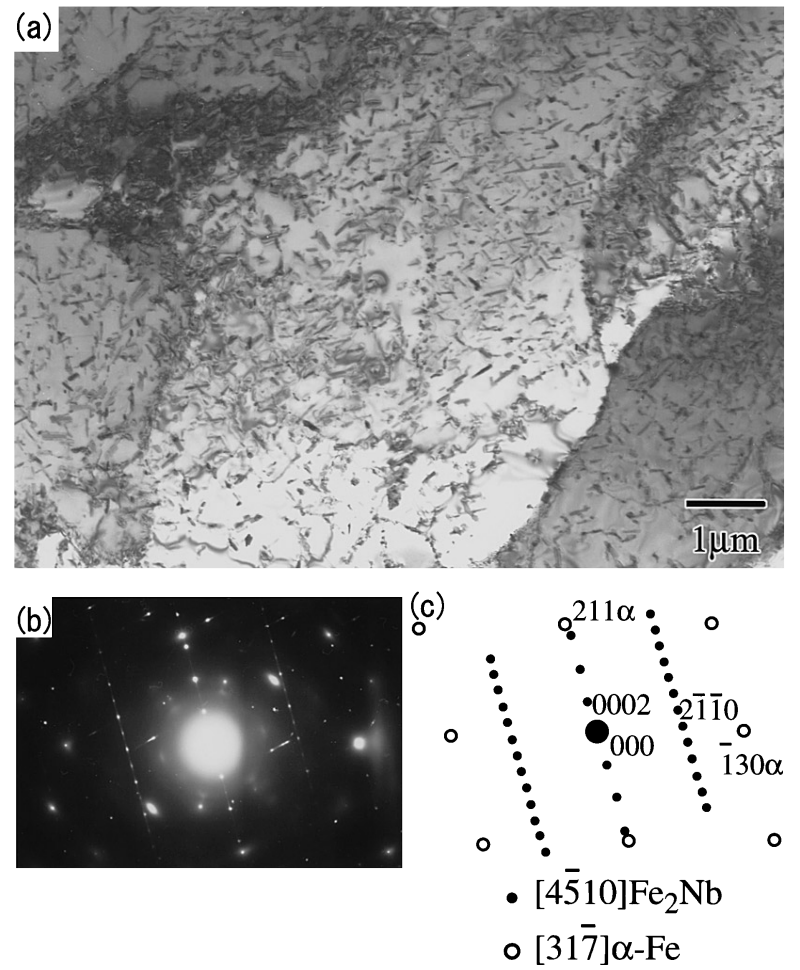

Fig. 3. (a) Bright field image of $10-0-\mathrm{F}$ alloy after aging at $1023 \mathrm{~K}$ for $1 \mathrm{~h}$, (b) SAD pattern, and (c) indexing of the SAD pattern.

here is the same as that of $\alpha$-Fe and $\mathrm{C} 14 \mathrm{Fe}_{2} \mathrm{~W}$ in the $\mathrm{Cr}-\mathrm{W}$ steels reported by Abe et al. and Murata et al. ${ }^{10,11)}$

The microstructure of the $10-1-\mathrm{MF}$ alloy annealed at $1023 \mathrm{~K}$ for $1 \mathrm{~h}$ is shown in Fig. 5. Recovery of the massive 


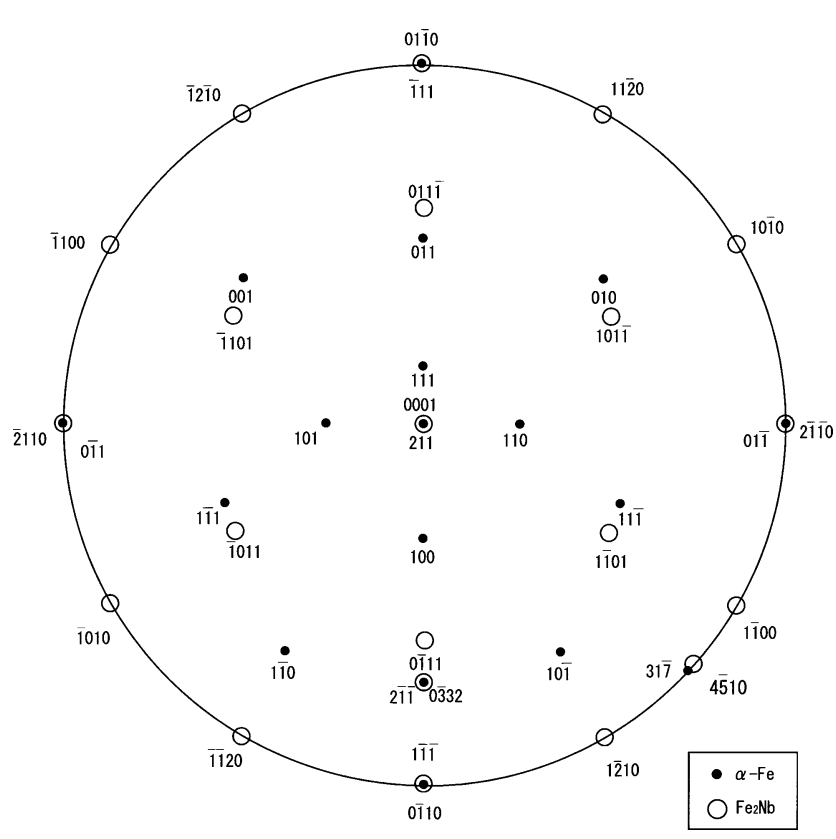

Fig. 4. Stereographic projection of the orientation relationship between $\alpha$-Fe and $\mathrm{Fe}_{2} \mathrm{Nb}, \mathrm{C} 14$ Laves phase.

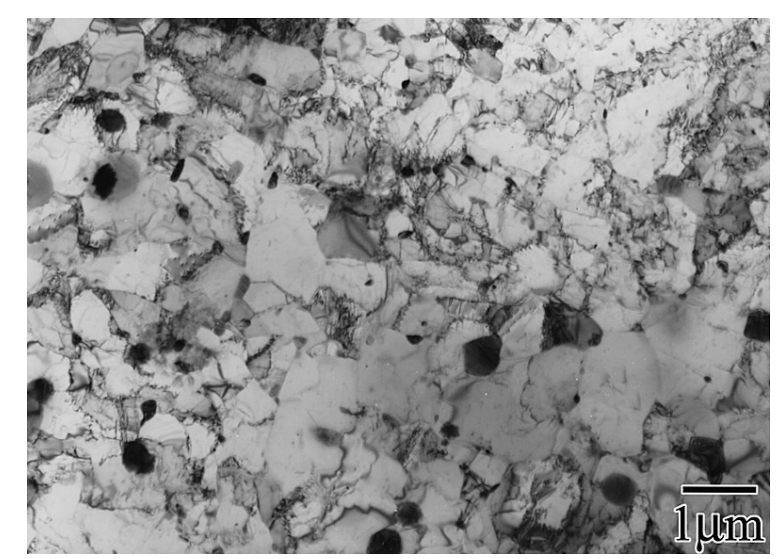

Fig. 5. Bright field image of $10-1-\mathrm{MF}$ alloy after aging at $1023 \mathrm{~K}$ for $1 \mathrm{~h}$.

ferrite and subgrain growth are the features of the annealed matrix compared with as-hot-rolled microstructure shown in Fig. 2(b). The $\mathrm{Fe}_{2} \mathrm{Nb}$ phase precipitates preferentially along subgrain boundaries, and they are thought to exert pinning force on subgrain boundaries. Comparing Fig. 3(a) with Fig. 5, it is found that extensively large volume fraction of $\mathrm{Fe}_{2} \mathrm{Nb}$ phase precipitates within grains of the 10-0-F alloy (Fig. 3(a)) but not of 10-1-MF alloy (Fig. 5) annealed at $1023 \mathrm{~K}$ for $1 \mathrm{~h}$. In $9 \mathrm{Cr}-\mathrm{W}$ steels, the $\mathrm{Fe}_{2} \mathrm{~W}$ Laves phase is known to precipitate extensively in ferrite rather than in martensite. ${ }^{10)}$

\subsubsection{Relationship between Microstructures and Tensile Properties}

To evaluate the effect of matrix substructure on static strength and elongation to failure, tensile tests at room temperature and at $873,973 \mathrm{~K}$ were conducted on as-hot-rolled and annealed $10-0-\mathrm{F}$ and $10-1-\mathrm{MF}$ alloys. The present annealing condition at $1023 \mathrm{~K}$ for $1 \mathrm{~h}$ is nearly the same heat treatment applied to commercial ferritic heat resistant steels with tempered martensite matrix. Figure 6 shows the temperature dependence of the tensile $0.2 \%$ flow stress and

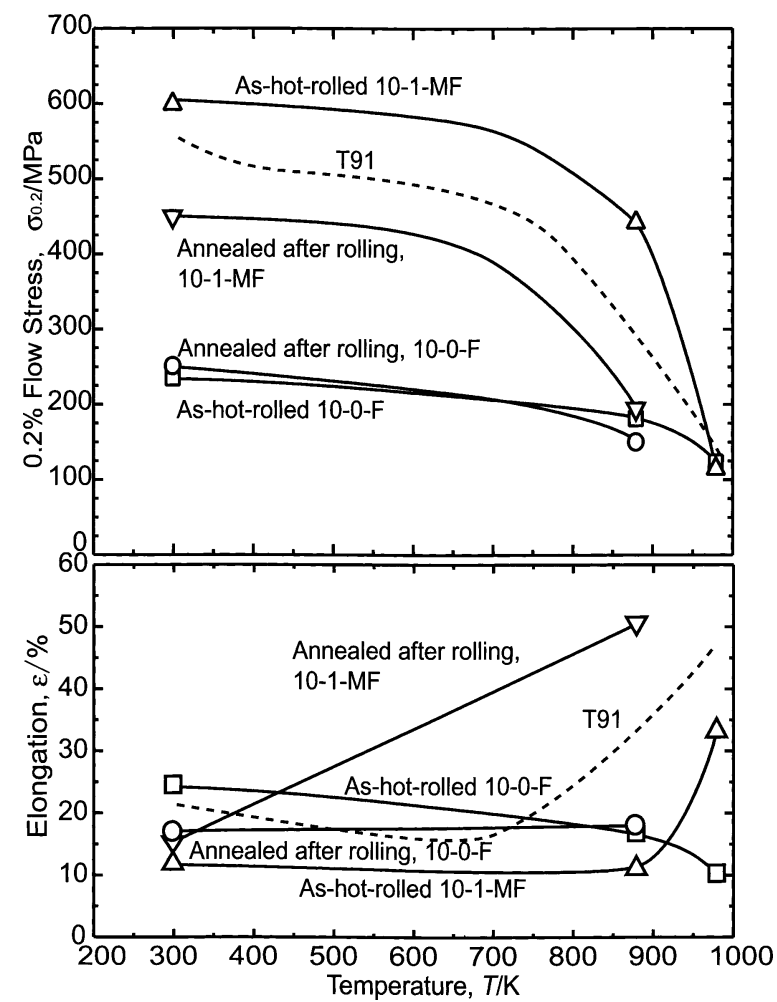

Fig. 6. Temperature dependence of the tensile $0.2 \%$ flow stress and elongation to failure of $10-0-\mathrm{F}$ and $10-1-\mathrm{MF}$ alloys for as-rolled and annealed at $1023 \mathrm{~K}$ for $1 \mathrm{~h}$. Data available for a commercial ferritic heat resistant, ASME SA213/SA-213M Grade T91 steel, are shown for comparison.

elongation to failure of the as-hot-rolled and annealed 10-0-F, 10-1-MF alloys. For comparison, those of the commercial ferritic heat resistant steel, ASME SA-213/SA213M Grade T91, based on tempered martensite matrix are shown together by broken lines in Fig. $6 .^{12)}$

By $1 \mathrm{~mol} \% \mathrm{Ni}$ addition, the tensile $0.2 \%$ flow stress of as-hot-rolled 10-1-MF alloy clearly increases and the elongation to failure decreases at room temperature as compared to the as-hot-rolled $10-0-\mathrm{F}$ alloy. It is attributed to the higher dislocation density in the matrix of 10-1-MF alloy than that of $10-0-F$ alloy as shown in Fig. 2. The strength of 10-1-MF alloy is also much higher than that of $10-0-\mathrm{F}$ alloy at $873 \mathrm{~K}$, however it is almost comparable at $973 \mathrm{~K}$ between both alloys. By annealing at $1023 \mathrm{~K}$ for $1 \mathrm{~h}$, the strength of 10-1-MF alloy considerably reduced while the elongation to failure is improved at room temperature. The annealed 10-1-MF alloy exhibits much lower strength and much higher elongation to failure than those of as-hotrolled alloy at $873 \mathrm{~K}$.

The strength of the as-hot-rolled 10-0-F alloys is almost temperature independent up to $973 \mathrm{~K}$. The reason would be that precipitation of $\mathrm{Fe}_{2} \mathrm{Nb}$ within grains occurs during holding about one hour prior to and upon the tensile tests at high temperatures and that it suppresses the decrease of strength. Fujita et al. indicated that precipitation of $\mathrm{Fe}_{2} \mathrm{Nb}$ in ferritic stainless steels during the tensile tests at $1223 \mathrm{~K}$ might contribute to high strength at elevated temperatures. ${ }^{13)}$ 


\subsection{Thermal Stability of Microstructure during Pro- longed Aging}

3.2.1. Changes in Microstructure and Hardness during Isothermal Aging

The thermal stability of the microstructure during long term exposure at high temperatures is very important for evaluating the durability of heat resistant steels since mechanical properties such as creep strength and toughness are strongly affected by the microstructures. Figure 7 shows the changes in Vickers hardness of 10-0-F, 10-1MF and 15-0-F alloys during isothermal aging at 873 and $973 \mathrm{~K}$ from 0.1 to $1000 \mathrm{~h}$. The hardness of $15-0-\mathrm{F}$ alloy is higher than that of $10-0-\mathrm{F}$ alloy even though they have the ferrite matrix in common and comparable amount of the Laves phase precipitation. Solid solution hardening by chromium is presumably higher in the $15-0-\mathrm{F}$ alloy than in the $10-0-\mathrm{F}$ alloy. The as-hot-rolled $10-1-\mathrm{MF}$ alloy with massive ferrite matrix has considerably high hardness as compared to the ferrite matrix alloys. This difference in hardness due to matrix substructures becomes smaller as the aging temperature and/or aging time increases, because the recovery of massive ferrite matrix proceeds in the 10 $1-\mathrm{MF}$ alloy during aging. Finally, the hardness of $10-1-\mathrm{MF}$ alloy becomes lower than that of the as-rolled state, and comparable to that of $10-0-\mathrm{F}$ alloy, after aging at $873 \mathrm{~K}$ for $1000 \mathrm{~h}$ and at $973 \mathrm{~K}$ as well.

The microstructures of $10-0-\mathrm{F}, 10-1-\mathrm{MF}$ and $15-0-\mathrm{F}$ alloys aged at 873 and $973 \mathrm{~K}$ for $1000 \mathrm{~h}$ are shown in Fig. 8. The microstructure of $10-0-\mathrm{F}$ alloy aged at $873 \mathrm{~K}$ contains high-density rod-shaped precipitates, less than $200 \mathrm{~nm}$ in length, existing in the ferrite matrix and on the subgrain boundaries. The size of the precipitates in the same alloy aged at $973 \mathrm{~K}$ is about $500 \mathrm{~nm}$ in length as shown in Fig. 8(b). Spherical Laves phase precipitates are observed in the subgrain boundaries in the $10-1-\mathrm{MF}$ alloy aged at $873 \mathrm{~K}$ as shown in Fig. 8(c). Comparing aging temperatures, the recovery of the matrix is more extensive at $973 \mathrm{~K}$ than at $873 \mathrm{~K}$ as clearly seen in Fig. 8(d); the subgrains are larger and the dislocation density is much lower in the alloy aged at $973 \mathrm{~K}, 8(\mathrm{~d})$, than at $873 \mathrm{~K}, 8(\mathrm{c})$. Figures $8(\mathrm{e})$ and $8(\mathrm{f})$ show bright field images of $15-0-\mathrm{F}$ alloy aged at 873 and $973 \mathrm{~K}$ for $1000 \mathrm{~h}$, respectively. The microstructures contain the rod-shaped precipitates within the ferrite matrix and in the subgrain boundaries, which is similar to the microstructures of the 10-0-F alloy shown in Figs. 8(a) and 8(b). By tilting experiment, it is confirmed that the precipitates are rod-shaped within ferrite matrix. It is noted that the shape of $\mathrm{Fe}_{2} \mathrm{~W}$ Laves phase within martensite lath is plate as reported by Murata et al. ${ }^{14)}$

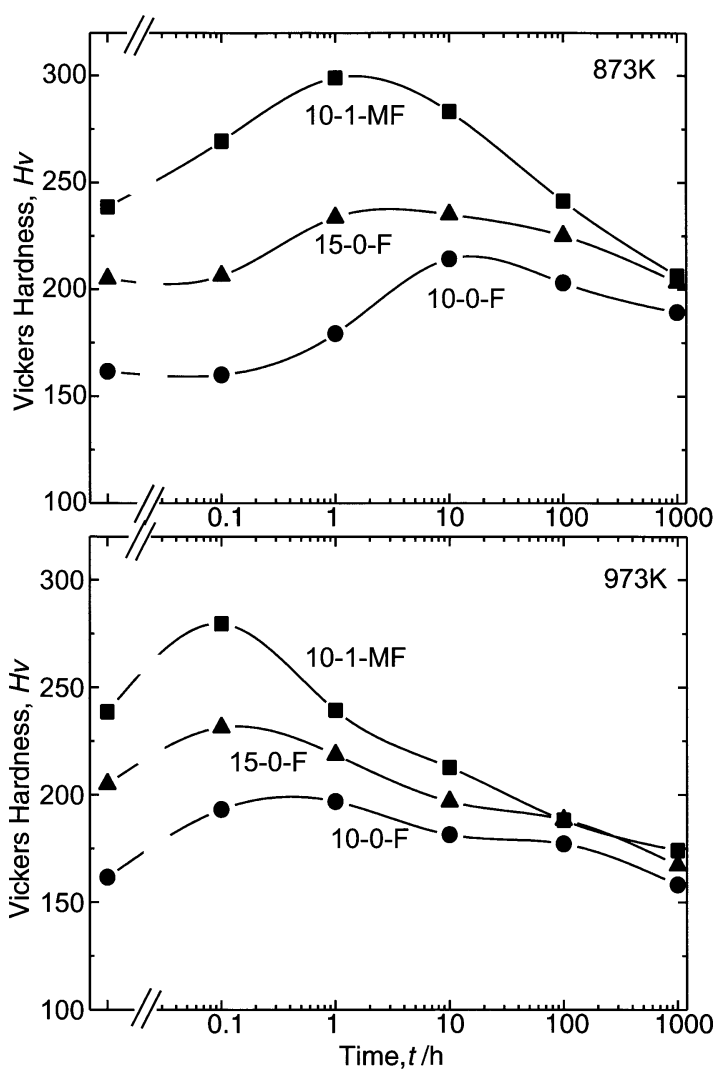

Fig. 7. Changes in Vickers hardness of the as-rolled 10-0-F, 10$1-\mathrm{MF}$ and $15-0-\mathrm{F}$ alloys as a function of isothermal aging at 873 and $973 \mathrm{~K}$.

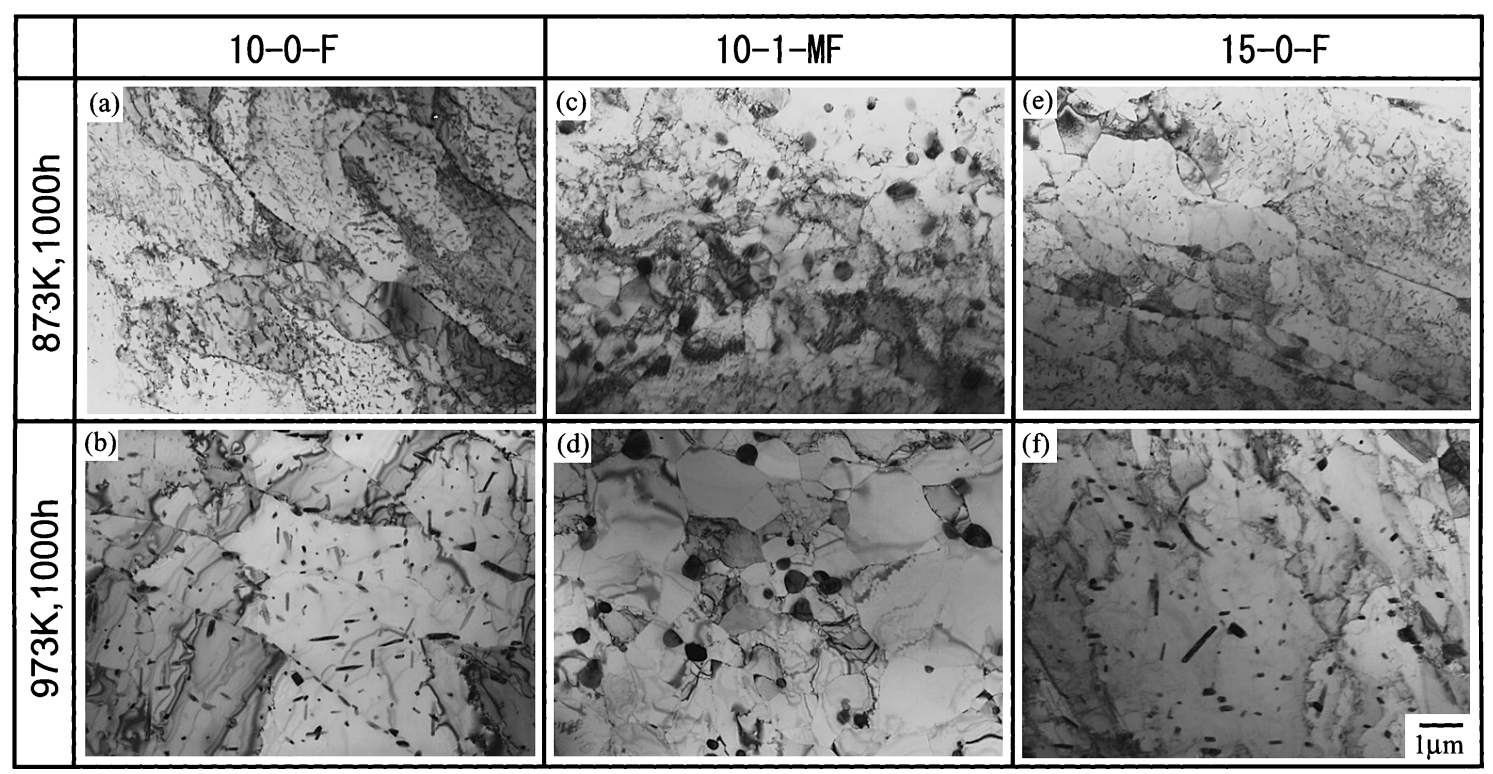

Fig. 8. Bright field images of $10-0-\mathrm{F}, 10-1-\mathrm{MF}$ and $15-0-\mathrm{F}$ alloys aged at 873 and $973 \mathrm{~K}$ for $1000 \mathrm{~h}$. 


\subsubsection{Consideration for Thermal Stability of Micro- structures}

The thermal stability of microstructures during aging of long duration more than $1000 \mathrm{~h}$ could be discussed in terms of the morphology and dispersion of the Laves phase precipitates. The precipitation of the Laves phase in the ferrite matrix has relatively uniform distribuition and rod-shaped morphology. These alloys maintain a high hardness level though slightly less than peak hardness even after aging for $1000 \mathrm{~h}$ at $873 \mathrm{~K}$. On the other hand in the massive ferrite matrix, the Laves phase precipitates in the subgrain boundaries with spherical morphology. Aging at $873 \mathrm{~K}$ for $1000 \mathrm{~h}$ is obviously the over-aged condition for this alloy. The hardness of the ferrite matrix alloys is almost equal to that of the massive ferrite matrix alloy after aging for $1000 \mathrm{~h}$ at both 873 and $973 \mathrm{~K}$, however it is speculated through the above discussion that the microstructures of ferrite matrix alloys would be more stable due to less coarsening of precipitates which are more uniformly distributed and less recovery of the matrix than those of the massive ferrite matrix alloys by comparing under the same aging condition at 873 and $973 \mathrm{~K}$ for over $1000 \mathrm{~h}$.

\subsection{Effect of Matrix Substructures on Precipitation of Laves Phase in the Fe-10Cr-1Nb-1Ni Alloy}

\subsubsection{Variation of Matrix Substructures}

As described in the Sec. 3.2, it is found that the age hardening behavior and precipitation morphology of the Laves phase in the Ni-free ferrite matrix alloys are considerably different from those in the massive ferrite matrix alloy with $\mathrm{Ni}$ addition. The number of available nucleation sites is thought to be provided depending on the dislocation density in the matrix substructure. To elucidate this speculation, the isothermal age hardening and precipitation morphology are investigated in the $\mathrm{Fe}-10 \mathrm{Cr}-1 \mathrm{Nb}-1 \mathrm{Ni}$ alloy for the three types of matrix substructures prepared by various heat treatments including compressive deformation. The matrix substructures and heat treatment conditions are listed in Table 3. As mentioned earlier, as-hot-rolled 10-1-MF alloy has the massive ferrite matrix as shown in the optical micrograph in Fig. 9(a). The alloy having ferrite matrix with large grain size as shown in Fig. 9(b) is prepared by the heat treatment of heating to $1573 \mathrm{~K}$ in the $\delta$-ferrite region for $1 \mathrm{~h}$ and subsequently quenching into water. By coldrolling with the reduction ratio of about $50 \%$ in thickness, the matrix becomes deformed ferrite which is characterized by the elongated ferrite grains with deformation bands as shown in Fig. 9(c).

\subsubsection{Precipitation of Laves Phase and Hardness Change of the Alloys}

The changes in hardness of the alloys with ferrite, massive ferrite and deformed ferrite matrix substructures during isothermal aging at $873 \mathrm{~K}$ are shown in Fig. 10. Particularly in the ferrite matrix alloy, the peak of hardness shifts to longer aging time in comparison with those in the massive ferrite matrix and deformed ferrite matrix alloys. The age-hardening behavior of deformed ferrite matrix alloy is almost the same as that of massive ferrite matrix alloy, although hardness of deformed ferrite matrix alloy is higher than that of massive ferrite matrix alloy.

Bright field images of the alloys with ferrite matrix and
Table 3. Characteristics of the matrix substructures in the $\mathrm{Fe}-10 \mathrm{Cr}-1 \mathrm{Nb}-1 \mathrm{Ni}$ alloy.

\begin{tabular}{c|l}
\hline Matrix & \multicolumn{1}{|c}{ Processing } \\
\hline Massive ferrite & Hot rolling W.Q. \\
Ferrite & Hot rolling W.Q.+1573K1h W.Q. \\
Deformed ferrite & Hot rolling W.Q.+1573K1h W.Q.+Cold rolling \\
\hline
\end{tabular}
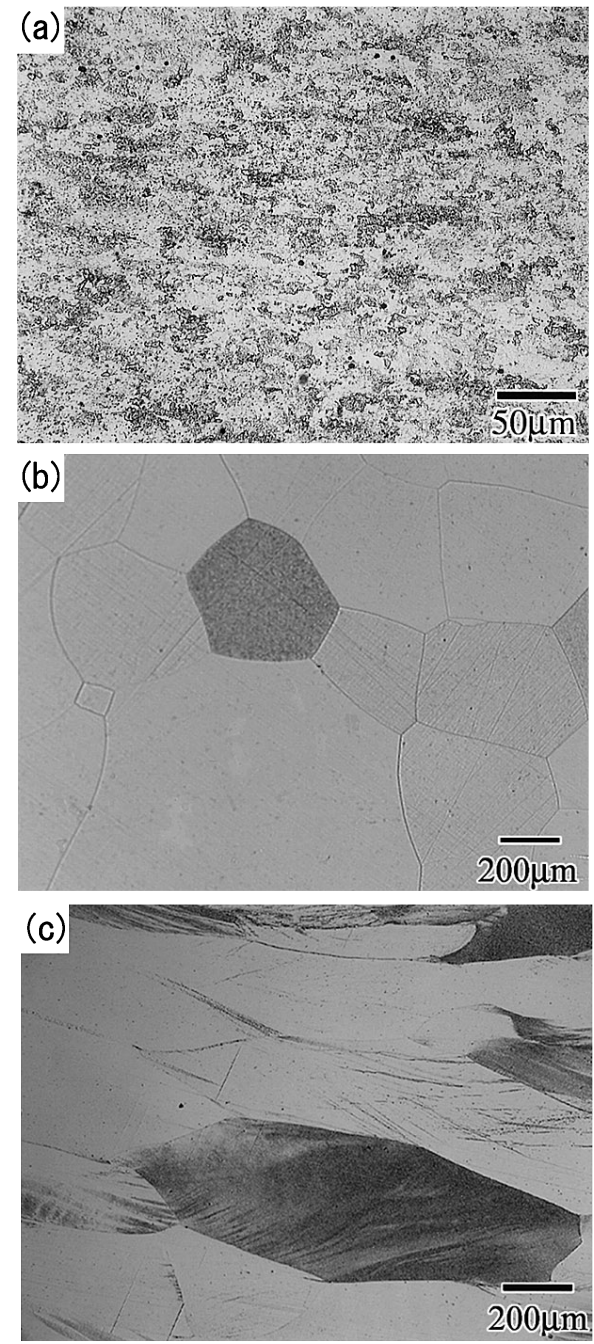

Fig. 9. Optical micrographs in the three types of matrix substructures in $\mathrm{Fe}-10 \mathrm{Cr}-1 \mathrm{Nb}-1 \mathrm{Ni}$ alloy, (a) massive ferrite, (b) ferrite and (c) deformed ferrite matrix.

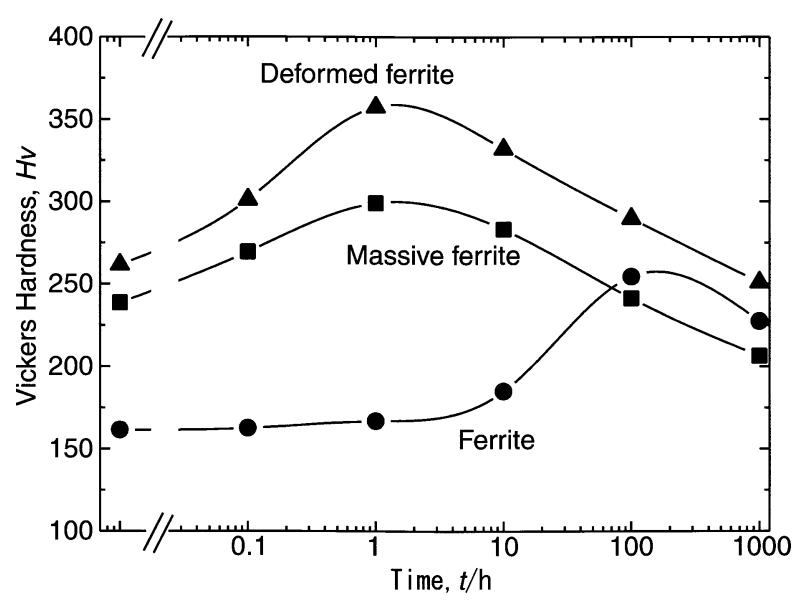

Fig. 10. Changes in Vickers hardness of massive ferrite, ferrite and deformed ferrite matrixes in $\mathrm{Fe}-10 \mathrm{Cr}-1 \mathrm{Nb}-1 \mathrm{Ni}$ alloy during isothermal aging at $873 \mathrm{~K}$. 

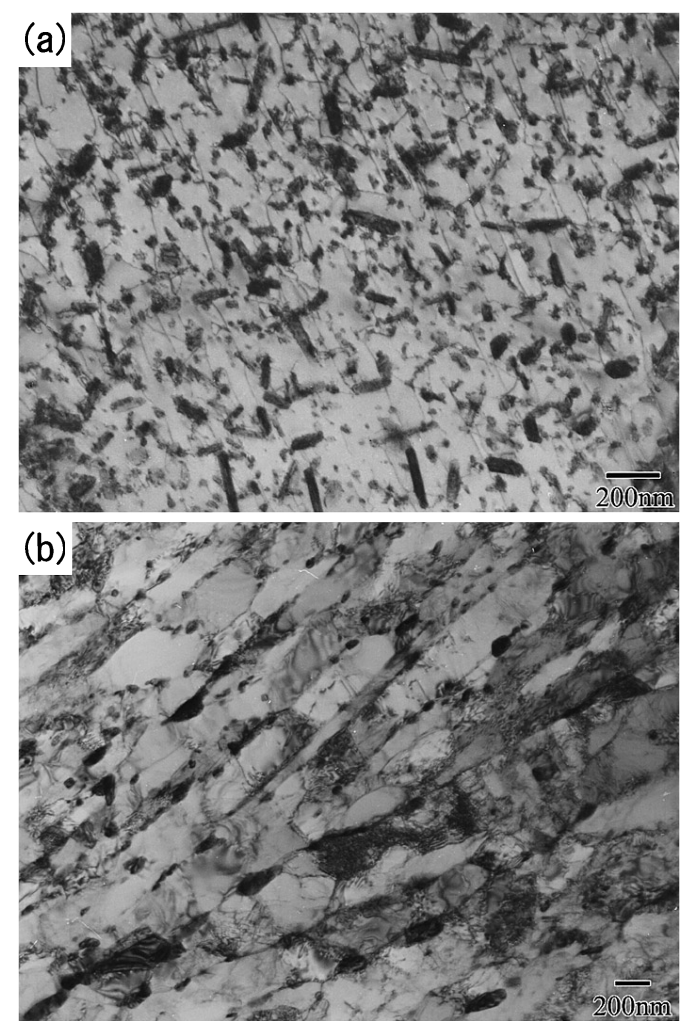

Fig. 11. Bright field images of $\mathrm{Fe}-10 \mathrm{Cr}-1 \mathrm{Nb}-1 \mathrm{Ni}$ alloy aged at $873 \mathrm{~K}$ for $1000 \mathrm{~h}$, (a) ferrite and (b) deformed ferrite matrix.

deformed ferrite matrix aged at $873 \mathrm{~K}$ for $1000 \mathrm{~h}$ are shown in Fig. 11. A large number of precipitates in the ferrite matrix are observed as shown in Fig. 11(a). The dislocation density in the ferrite matrix is low and the shape of the precipitates is rod-shaped. In the deformed ferrite matrix, the Laves phase preferably precipitates in the subgrain boundaries as shown in Fig. 11(b). It is assumed that the substructure of deformed ferrite matrix changes from dislocation cell structures to subgrain structures by recovery during aging. It is found that the difference of matrix substructures between the ferrite and the deformed ferrite provides the different number and distribution of nucleation sites for precipitation of the Laves phase. In the deformed ferrite matrix, the coarse Laves phase preferably precipitates in the subgrain boundaries, which is similar to the case in the alloy with massive ferrite matrix. Therefore there seems to be no obvious difference between the massive ferrite and the deformed ferrite in respect of the number and distribution of nucleation sites at subgrain boundaries. While in the alloy with the ferrite matrix, rather small Laves phase precipitates uniformly in the matrix and the microstructure is more stable than the other two alloys.

\section{Conclusions}

Effect of the matrix substructures; ferrite, massive ferrite and deformed ferrite, on precipitation of $\mathrm{C} 14$ Laves phase was studied in $\mathrm{Fe}-\mathrm{Cr}-\mathrm{Nb}-\mathrm{Ni}$ system.
The following conclusions are drawn from the present work.

(1) The microstructures of as-hot-rolled $10-0-\mathrm{F}$ and 15-0-F alloys consist of the ferrite matrix and a small amount of $\mathrm{Fe}_{2} \mathrm{Nb}$ particles, since those alloys have no $\gamma / \alpha$ transformation. The microstructure of as-hot-rolled 10-1MF alloy consists of the massive ferrite matrix with high dislocation density and spherical $\mathrm{Fe}_{2} \mathrm{Nb}$ precipitates.

(2) The microstructure of the alloy with the ferrite matrix contains high density of rod-shaped Laves phase which precipitates within the ferrite grains during annealing at $1023 \mathrm{~K}$ for $1 \mathrm{~h}$. On the other hand in the massive ferrite matrix, most of the Laves phase precipitates in the subgrain boundaries.

(3) $0.2 \%$ flow stress in tensile test of $10-1-\mathrm{MF}$ alloy with high dislocation density is much higher than that of $10-0-\mathrm{F}$ alloy up to $873 \mathrm{~K}$, however it is almost comparable at $973 \mathrm{~K}$ between both alloys.

(4) The hardness of 10-1-MF alloy decreases because of the recovery of massive ferrite matrix as the aging temperature and/or aging time increases. Finally, the hardness of this alloy after aging at 873 and $973 \mathrm{~K}$ for $1000 \mathrm{~h}$ is almost equal to those of $10-0-\mathrm{F}$ and $15-0-\mathrm{F}$ alloys. It is suggested that high temperature strength can be maintained for long duration in the ferrite matrix alloys because of relatively uniform dispersion of the precipitations.

(5) In comparison of aging behavior in the massive ferrite, the ferrite and the deformed ferrite matrix in the $\mathrm{Fe}-$ $10 \mathrm{Cr}-1 \mathrm{Nb}-1 \mathrm{Ni}$ alloy, the age-hardening behavior and morphology of precipitates in the deformed ferrite matrix is almost the same as that of the massive ferrite. The difference between the ferrite and the deformed ferrite matrix is the number and distribution of nucleation sites for the Laves phase precipitates.

\section{REFERENCES}

1) J. Hald: Steel Res., 67 (1996), 369.

2) H. Uchida, M. Fujiwara and S. Ohta: Tekkoudaigakusi, 19 (1985), 17.

3) K. H. Mayer, H. Cerjak, T. Kern, M. Staubli and D. V. Thornton: Proc. of the Int. Workshop on the Innovative Structural Materials for Infrastructure in 21st Century "Ultra-Steel 2000", NRIM Tsukuba, (2000), 65

4) Y. Hosoi, N. Wade, S. Kunimitsu and T. Urita: Tetsu-to-Hagané, 76 (1990), 1116.

5) T. Suzuki: Bull. Jpn. Inst. Met., 11 (1972), 649.

6) N. Maruyama, M. Sugiyama, T. Hara and H. Tamehiro: Mater. Trans. JIM, 40 (1999), 268

7) K. Yamamoto, Y. Kimura, F. G. Wei and Y. Mishima: Mater. Sci. Eng., A329-331 (2002), 249.

8) H. Sudo: Steel, JIM, Sendai, (1985), 45.

9) G. Krauss and S.W. Thompson: ISIJ Int., 35 (1995), 937.

10) F. Abe, H. Araki and T. Noda: Metall. Trans. A., 22A (1991) 2225

11) Y. Murata, M. Morita, R. Hashizume, K. Takami, T. Azuma, Y. Tanaka and T. Ishiguro: Mater. Sci. Eng., A282 (2000), 251.

12) NRIM Materials strength sheet. 43 (1996)

13) N. Fujita, K. Ohmura, M. Kikuchi, T. Suzuki, S. Funaki and I. Hiroshige: Scr. Mater, 35 (1996), 705.

14) Y. Murata, K. Takami, M. Kamiya, M. Morinaga, R. Hashizume, K. Miki, T. Azuma and T. Ishiguro: Tetsu-to-Hagané, 88 (2002), 214 